\title{
Inhaltsverzeichnis
}

Einleitung

1. Etymologie als Begriff und Verfahren

2. Diachronische und synchronische Etymologie

3. Einsprachige und mehrsprachige Etymologie 11

4. Objektsprachliche und metasprachliche Etymologie 14

1. Antike und mittelalterliche Etymologie zwischen Sinndeutung und Rhetorizität

2. Frühneuzeitliche Etymologie zwischen Nationalsprache und Sprachenvergleich

3. Aufklärerische Kritik und Fortschreibung der Etymologie

1. "Neue Empirizitäten«

2. Spekulativität der Empirie
a. Frühromantische Philologieentwürfe
87
b. Grammatische Struktur
94
c. Offenbarte Sprache
99

\section{VERGLEICHENDE VERFAHREN: ETYMOLOGIE} IN DER ROMANTISCHEN MYTHOGRAPHIE

1. Rhetorisierung des Mythos: Romantische Mythographie und Neue Mythologie

2. Etymologische Topik

a. Vergleichbarkeit der Mythen

b. Verräumlichung der »Mythengeschichte»

3. Etymologische Tropik

b. Etymologie als Zeugung, Magie und Witz

c. Etymologie als Distanz zum Ursprung 
V. WURZELN DES DEUTSCHEN: ETYMOLOGIE BEI FRIEDRICH RÜCKERT UND JOHANN KAINDL

1. Friedrich Rückerts Dissertatio philologico-philosophica de idea philologiae 172

a. Idee der Philologie als Philologie der Idealsprache 174

b. Das Deutsche als Idealsprache: Rückerts Übersetzungstheorie 181

c. Rückerts Poetik der Etymologie $\quad 185$

2. Johann Evangelist Kaindls Teutsche Sprache aus ibren Wurzen 200

a. Ursprachlichkeit der Wurzeln $\quad 201$

b. Etymologie und Alphabet $\quad 204$

VI. EXKURS: ETYMOLOGIE IN DER

ROMANTISCHEN LITERATUR 212

VII. SCHNEEFALL DER WÖRTER: ETYMOLOGIE

BEI JACOB GRIMM 238

1. Die Metonymisierung der Sprachen $\quad 239$

a. Verkettungen des Mythos $\quad 239$

b. Verwicklungen in den Ursprung 250

2. Die Ordnung der Wörter 259

a. Regulierungen der Etymologie $\quad 259$

b. Etymologie im Wörterbuch 262

Schluß: Wissenspoetik und Wörtlichkeit 276

ANHANG

$\begin{array}{ll}\text { Literaturverzeichnis } & 281\end{array}$

$\begin{array}{ll}\text { Sachverzeichnis } & 307\end{array}$

Namenverzeichnis $\quad 312$

$\begin{array}{ll}\text { Ausführliches Inhaltsverzeichnis } & 320\end{array}$ 